\title{
The depuration fate of the mixtures of CdS/ ZnS quantum dots (QDs) with different surface coatings on mangrove and wheat root epidermis: results from a novel method
}

\author{
Ruilong $\mathrm{Li}^{1,2,3 \dagger}$, Shuaipeng Zhang ${ }^{1,2,3 \dagger}$, Yinghui Wang ${ }^{1,2,3^{*}}$ and Kefu Yu1,2,3*
}

\begin{abstract}
Background: The depuration fate of mixtures of metal-based quantum dots (QDs) in root epidermis is an important factor that determined their follow-up transportation and transformation processes in plant. However, the related mechanisms are poorly understood due to the lack of appropriate quantitative methods.

Results: In our study, a novel method for in situ determination of mixtures of CdS/ZnS QDs with different surface coatings located on root epidermis was developed using an excitation-emission matrix combined with multi-way parallel factor analysis (PARAFAC) and n-way partial least squares ( $n$-PLS). Then, the fates of CdS/ZnS QDs on mangrove and wheat root epidermis were investigated using the established method. During the rapid dissipation stage, intracellular and intercellular degradation of metal ions instead of transportation and rhizophytic bacteria degradation was the predominant reasons for the reduction in the CdS/ZnS QDs mixtures. However, due to vertical migration of CdS/ZnS QDs in the slow depuration stage, negative linear relationships were observed between the $K_{\mathrm{s}}$ values of oleic acid-CdS/ZnS QDs and the polarity index of the root epidermis $(p<0.05)$, which further indicated a difference between the single and mixture QDs.
\end{abstract}

Conclusions: To our knowledge, this study provided a new approach to investigate the fate of QDs located on root epidermis and revealed the related mechanisms.

Keywords: Depurations, Mixture, CdS/ZnS QDs, In situ

\section{Background}

Semiconductor quantum dots (QDs) have been classified as a new class of engineered nanomaterials (ENMs), which are used in many applications due to their unique optical and electrical properties [1-3], and global production reached $55 \mathrm{t} / \mathrm{y}$ in $2012[4,5]$. The growing prevalence of QDs, especially metal-based QDs, in conjunction with the risk of unwanted/unanticipated biota exposure renders them a potential concern [6,7]. For example,

\footnotetext{
*Correspondence: wyh@gxu.edu.cn; kefuyu@scsio.ac.cn

${ }^{\dagger}$ Ruilong Li and Shuaipeng Zhang are co first authors and equally contributed to this work

1 School of Marine Sciences, Guangxi University, Nanning 530004, People's Republic of China

Full list of author information is available at the end of the article
}

Pasquali et al. demonstrated that a variety of negative effects, including increased reactive oxygen species levels and decreased glutathione levels, were observed in Saccharomyces cerevisiae yeast cells after exposure to CdS QDs [8]. Modlitbová et al. confirmed that the toxicity of CdTe QDs is similar to that of $\mathrm{CdCl}_{2}$ for the model plant Allium cepa L. [9].

ENM uptake by roots, including metal-based QDs, has been confirmed to be one of the most important pathways for plant contamination and subsequent biota exposure through the food chain [10-12]. Al-Salim et al. first confirmed that four different surface coatings (cysteine-, mercaptosuccinic acid-, glycine- and amine-conjugated) of CdS/ZnS QDs were transported to the limited zones in onion (Allium cepa), chrysanthemum (Chrysanthemum 
sp.) and ryegrass (Lolium perenne) roots [13]. The results from in situ two-photon laser confocal scanning fluorescence microscopy (TPLCSM) further validated that the root epidermis was the limiting zone for nearly all of the remaining $\mathrm{N}$-acetyl cysteine-coated CdS:Mn/ZnS QDs [14].

However, some recent studies have demonstrated that ENMs located on the root epidermis are not stable and are easily depurated through many pathways $[15,16]$. For example, $\mathrm{CeO}_{2}$ nanoparticles (NPs) are partly biotransformed from $\mathrm{Ce}(\mathrm{IV})$ to $\mathrm{Ce}(\mathrm{III})$ in the root surface of hydroponic plants with the aid of the interactions between the NPs and root exudates [17]. Montes et al. concluded that other kinds of metal NPs, including polyacrylic acid (PAA)-/polyethylenimine (PEI)-coated $\mathrm{Fe}_{2} \mathrm{O}_{3}$ and $\mathrm{TiO}_{2} \mathrm{NPs}$, displayed similar depuration behaviors on Arabidopsis thaliana root epidermis [18]. In this respect, metal-based QDs located on root epidermis may undergo degradation, desorption and transportation processes. However, until now, no corresponding studies have confirmed our assumption and the contributions of individual processes to total depuration. Moreover, metal-based QDs with different surface coatings often exist as a mixture in soil/sediment and water [19]. Due to their different physicochemical characteristics, the interactions of different kinds of ENMs in higher plant roots may directly induce changes in the selective substance transmembrane transport kinetics of the plasma membrane $\mathrm{H}^{+}$-ATPase [20, 21], which also needs special attention.

Limited by an appropriate quantification analytical method, few studies have focused on investigating the depuration of mixture CdS/ZnS QDs located on the root epidermis. Inductively coupled plasma-mass spectrometry (ICP-MS) has long been considered as an effective approach to determine trace concentrations of metalbased QDs in environmental samples, including water, soil/sediment and biota [22-24]. However, the ICPMS method does not yet possess the spatial resolution required for completely degraded QDs in environmental samples, which occurs during pretreatment procedures, $[25,26]$ and thus, the method cannot quantify this fraction of metal-based QDs.

As the metal-based QDs have high fluorescence quantum yield, the single wavelength fluorescence spectra combined with fluorescence microscopy techniques have been widely used to in situ determine the metalbased QDs in specific locations of environmental samples $[27,28]$. Unfortunately, further studies have demonstrated that the sensitivity and selectivity of this standard fluorescence spectroscopy method significantly decrease in the presence of the strong autofluorescence of root tissues [29]. To overcome such drawbacks, an in situ accurate nanosecond time-resolved fluorescence spectroscopy (NTFS) method was recently established to detect $\mathrm{CdS} / \mathrm{ZnS}$ QDs located on mangrove root epidermis. The detection limits are as low as 1.2-2.0 ng/spot for CdS/ZnS QDs with different surface coatings [30]. Nevertheless, the excitation-emission and time-resolved fluorescence spectra of the QDs overlapped, and thus, determining mixtures of metal-based QDs located on root epidermis is impossible.

As Carabajal et al. reported, parallel factor analysis (PARAFAC) and n-way partial least squares (n-PLS) based on excitation-emission matrix fluorescence spectra have been used to quantify mixture components with strong fluorescence signals [31]. For example, Yang et al. simultaneously identified and quantified multiple components of polycyclic aromatic hydrocarbons (PAHs) in the presence of humic acids with similarities above 0.980 for the resolved and reference spectra [32]. Therefore, combining the PARAFAC/n-PLS technique with the NTFS method may provide the ability to establish a novel in situ quantification method for mixtures of metal-based QDs that well fits our requirements.

The objectives of this study were to (1) improve the selectivity of the NTFS method to fit the requirements to determine the mixtures of $\mathrm{CdS} / \mathrm{ZnS}$ QDs, (2) investigate the depuration fate of the mixtures of $\mathrm{CdS} / \mathrm{ZnS}$ QDs located on root epidermis and (3) further explore the related mechanisms of mixtures of $\mathrm{CdS} / \mathrm{ZnS}$ QDs depurated on the root epidermis. Mixtures of $\mathrm{CdS} / \mathrm{ZnS}$ QDs with different surface coatings (oleic acid-, PEG$\mathrm{COOH}-$ and MPA-COOH-) were selected as the model mixture CdS/ZnS QDs.

\section{Materials and methods \\ Reagents}

Oleic acid-CdS/ZnS QDs, PEG-COOH-CdS/ZnS QDs and MPA-COOH-CdS/ZnS QDs were purchased from Xingshuo Co., Ltd. (China). These QDs have a fluorescence emission peak at $400-460 \mathrm{~nm}$ and a half-peak width of less than $25 \mathrm{~nm}$. All other reagents in this study were analytical-grade reagents (A.R.) obtained from Sinopharm Chemical Reagent Co., Ltd. (China).

\section{Cultivation of the model plant}

The wheat seeds (Triticum acstivnm L.) and mangrove (Kandelia obovata (S., L.) Yong) hypocotyl were immersed into $10 \% \mathrm{H}_{2} \mathrm{O}_{2}(\mathrm{v} / \mathrm{v})$ and subsequently Milli$\mathrm{Q}$ water three times. Then, the seeds were germinated on moist filter paper in a growth chamber (Safu Co. Ltd, China) under a light intensity of $200 \mu \mathrm{mol} \mathrm{m}^{-2} \mathrm{~s}^{-1}$ with a light cycle of $14 / 10 \mathrm{~h}$ (day/night) and constant temperature $(298.15 \pm 1 \mathrm{~K})$. After 7 days, several mature plants 
with nearly the same heights were selected for further studies.

\section{Establishing in situ determination of mixture CdS/ZnS QDs located on root epidermis}

The mangrove (Kandelia obovata (S., L.) Yong) and wheat seedlings (Triticum aestivum L.) were carefully cleaned with tap water, distilled water and Milli-Q water three times for approximately $10 \mathrm{~min}$. After air drying, the plants were transferred into $500-\mathrm{mL}$ beakers containing graded mixtures of the $\mathrm{CdS} / \mathrm{ZnS}$ QD series [total concentrations $\left(C_{\mathrm{t}}\right): 30 \mu \mathrm{g} / \mathrm{L}, 60 \mu \mathrm{g} / \mathrm{L}, 90 \mu \mathrm{g} / \mathrm{L}, 120 \mu \mathrm{g} / \mathrm{L}$ and $300 \mu \mathrm{g} / \mathrm{L}$ ] for $6 \mathrm{~h}$. The residual concentrations of the $\mathrm{CdS} / \mathrm{ZnS}$ QDs in aqueous solution $\left(C_{\mathrm{r}}\right)$ were determined using the synchronous fluorescence spectra methods (the detailed information of this method was presented in the experimental section of Additional file 1) [33], and the contents of CdS/ZnS QDs adsorbed onto the roots $\left(C_{\mathrm{s}}\right)$ were calculated by the equation $C_{\mathrm{s}}=C_{\mathrm{t}}-C_{\mathrm{r}}$.

Then, the contaminated roots were placed under a nanosecond time-resolved spectrofluorimeter (Edinburgh FLS 980, UK) equipped with a $450 \mathrm{~W}$ Xe lamp. The experimental set-ups were similar to our previously reported [29]. Other key parameters are as follows: excitation wavelength, 390-410 nm; emission wavelength, 420-550 nm; delay time, $30 \mathrm{~ns}$; light frequency, $40 \mathrm{MHz}$; and collection time, $5.00 \mathrm{~s}$. All of the acquired excitationemission fluorescence matrixes were processed under the Matlab environment. The N-way toolbox combined with the n-PLS algorithm, as previously described by Yang et al. [34], was used to split the fluorescence of the CdS/ ZnS QD mixtures located on the root epidermis. Finally, the linear ranges, detection limits and relative standard deviations of the novel established method were acquired based on our previously reported methods [35].

\section{The fate of the mixture CdS/ZnS QDs located on the epidermis of roots}

After cleaning up the seedlings with Milli-Q water three times, nine groups of mangrove (Kandelia obovata (S., L.) Yong) and wheat (Triticum acstivnm L.) seedlings were immediately divided into two groups: with and without sterilized treatment. The in vitro-sterilized treatments were similar to those reported [36]. Briefly, the roots were sequentially immersed in $200 \mathrm{~mL}$ of $99 \%$ (v/v) ethanol for $1 \mathrm{~min}, 100 \mathrm{~mL}$ of $3.125 \%(\mathrm{v} / \mathrm{v})$ sodium hypochlorite for $6 \mathrm{~min}, 200 \mathrm{~mL}$ of $99 \%(\mathrm{v} / \mathrm{v})$ ethanol for $0.5 \mathrm{~min}$ and $500 \mathrm{~mL}$ of sterile reverse osmosis-treated (RO) water. Then, these two groups were transferred to 500 -mL beakers containing $400 \mathrm{~mL}$ of full-strength Hoagland nutrient solution $(\mathrm{pH}=5.5)$ with mixtures of $\mathrm{CdS} / \mathrm{ZnS}$ QDs with three different surface coatings (oleic acid-CdS/ZnS QDs:
$40 \mu \mathrm{g} / \mathrm{L}$, PEG-COOH-CdS/ZnS QDs: $100 \mu \mathrm{g} / \mathrm{L}$, MPACOOH-CdS/ZnS QDs: $100 \mu \mathrm{g} / \mathrm{L})$. Another two groups of mangrove (Kandelia obovata (S., L.) Yong) and wheat (Triticum acstivnm L.) seedlings contaminated with monocomponent CdS/ZnS QDs were selected as the control groups.

After the exposure procedures, the CdS/ZnS QDs located on the root epidermis were allowed to be transported and degraded for $1 \mathrm{~h}, 2 \mathrm{~h}, 4 \mathrm{~h}, 8 \mathrm{~h}, 16 \mathrm{~h}, 36 \mathrm{~h}, 72 \mathrm{~h}$, $120 \mathrm{~h}$ and $168 \mathrm{~h}$ in aqueous solutions. At each sampling point, the $\mathrm{CdS} / \mathrm{ZnS}$ QD concentrations were determined using the novel method established in our study. The experiments were conducted over a 7-day period at a day/night time (16/8) with day/night temperatures of $293.15 \pm 1 \mathrm{~K}$ and $298.15 \pm 1 \mathrm{~K}$, respectively, and relative humidity of $60 \%$.

\section{Characterization of the mangrove and wheat roots}

Prior to the analysis of the root characteristics, the root samples were fixed according to a previously reported method [35]. The procedures are briefly described as follows. First, approximately, $2 \mathrm{~g}$ of sample was immersed in $2.5 \%$ glutaraldehyde in a $0.1 \mathrm{mmol} / \mathrm{L}$ phosphate buffer $(\mathrm{pH}=7.2)$ for $8 \mathrm{~h}$. Second, the sample was dehydrated in a graded ethanol series $(30 \%, 50 \%, 70 \%, 80 \%, 90 \%$ and $100 \%$ ), and then, the solvent was replaced by $t$-butanol. Third, to acquire a new intact surface, the root samples were cut into slices using a sterile knife under liquid nitrogen conditions. Finally, the spatial arrangement of the functionalities and morphologies of the roots was obtained using a JXA-8230 field emission scanning electron microscope (JEOL, Japan) combined with an energy-dispersive spectrometer (EDS).

To obtain the Cd content in the roots, the inductively coupled plasma-mass spectrometry (ICP-MS) method was used with some modification [37]. Briefly, root tissue below the liquid level was first dried at $60 \pm 2{ }^{\circ} \mathrm{C}$ for $24 \mathrm{~h}$. Then, the samples were microwave digested using $5 \mathrm{~mL}$ of $\mathrm{HNO}_{3}$ and $1 \mathrm{~mL}$ of $\mathrm{H}_{2} \mathrm{O}_{2}$ and then directly analyzed by ICP-MS (Thermo Fisher, ICAP-Qc).

\section{Statistical analysis}

All data presented in this study are the mean values of six replicates. The mean and standard deviation values of the replicates were calculated and compared by one-way analysis of variance (ANOVA) tests. All statistical analyses were run using SPSS version 19.0 software.

\section{Results and discussion}

Establishing an in situ method to determine the content of CdS/ZnS QDs located on root epidermis

Prior to establishing the in situ method, the standard emission fluorescence spectra of uncontaminated 
mangrove (Kandelia obovata (S., L.) Yong) and wheat (Triticum acstivnm L.) root epidermis samples were obtained and are presented in Additional file 1: Figure S1. Clearly, this technique is not suitable for determining the contents of CdS/ZnS QDs because of the presence of a strong autofluorescence signal from the roots and fluorescence signals from nontarget components. To reduce these interferences, as previously reported [38], the short lifetime fluorescence signal measurements were subtracted, and the signal/noise $(\mathrm{S} / \mathrm{N})$ rates increased about 7.06-19.11 times for CdS/ZnS QDs located on the mangrove (Kandelia obovata (S., L.) Yong) root epidermis at the optimal excitation/emission wavelength, which fit our requirements (Additional file 1: Table S1). Similar results were obtained for wheat (Triticum acstivnm L.) root samples. However, overlap still exists between the fluorescence spectra of the three kinds of CdS/ZnS QDs in the emission wavelength range of $420 \mathrm{~nm}-650 \mathrm{~nm}$.

To validate the accuracy of the PARAFAC model, smaller data sets comprised of samples containing only one standard showed satisfactory data for these three $\mathrm{CdS} / \mathrm{ZnS}$ QDs located on mangrove (Kandelia obovata (S., L.) Yong) root epidermis after deduction of the short lifetime fluorescence signal $(<10 \mathrm{~ns}$, Additional file 1: Figure S2). Similar results were obtained for wheat (Triticum acstivnm L.) (Additional file 1: Figure S3). In addition, negligible fluctuations existed for the relative fluorescence intensity and optimal emission/excitation wavelength (Oleic acid-CdS/ZnS QDs, $\lambda_{\text {ex }} / \lambda_{\text {em }}=398 \mathrm{~nm} / 482 \mathrm{~nm}$; PEG-COOH-CdS/ZnS QDs, $\lambda_{\mathrm{ex}} / \lambda_{\mathrm{em}}=345 \mathrm{~nm} / 498 \mathrm{~nm}$; MPA-COOH-CdS/ZnS QDs, $\left.\lambda_{\text {ex }} / \lambda_{\text {em }}=368 \mathrm{~nm} / 516 \mathrm{~nm}\right)$. The above results demonstrated that the PARAFAC technique can distinguish the fluorescence spectra of these three CdS/ZnS QDs in situ, even with strong spectral overlap (Additional file 1: Figure S1). Additionally, a value of $R^{2}=1$ indicates that two spectra are exactly the same. In our study, high correlation coefficient $\left(R^{2}\right)$ values were obtained between the fluorescence spectra retrieved from the mixtures by the PARAFAC model and the fluorescence spectra of single CdS/ZnS QDs, and the results are listed in Table 1.

After applying the n-PLS algorithm, the relative concentration of $\mathrm{CdS} / \mathrm{ZnS}$ QDs located on mangrove

Table 1 Nanosecond time-resolved fluorescence spectra correlation coefficient $\left(R^{2}\right)$ for the three-way PARAFAC model

\begin{tabular}{llll}
\hline Plant & $\begin{array}{l}\text { Oleic acid-CdS/ } \\
\text { ZnS QDs }\end{array}$ & $\begin{array}{l}\text { PEG-COOH-CdS/ } \\
\text { ZnS QDs }\end{array}$ & $\begin{array}{l}\text { MPA-COOH- } \\
\text { CdS/ZnS } \\
\text { QDs }\end{array}$ \\
\hline Mangrove & 0.9983 & 0.9947 & 0.9990 \\
Wheat & 0.9976 & 0.9932 & 0.9969 \\
\hline
\end{tabular}

(Kandelia obovata (S., L.) Yong) root epidermis and its relationship with the practical concentration were determined with the correlation coefficients of 0.9987 , 0.9978 and 0.9973 for the oleic acid-CdS/ZnS QDs, PEG-COOH-CdS/ZnS QDs and MPA-COOH-CdS/ $\mathrm{ZnS}$ QDs, respectively (Fig. 1). For wheat (Triticum acstivnm L.), the correlation coefficients were 0.9966, 0.9969 and 0.9986 for oleic acid-CdS/ZnS QDs, PEG$\mathrm{COOH}-\mathrm{CdS} / \mathrm{ZnS}$ QDs and MPA-COOH-CdS/ZnS QDs, respectively (Additional file 1: Figure S4). A three-factor model provided a \%fit in the range of $98.39-99.31 \%$ and 98.25-99.53\% and a core consistency in the ranges of 99.08-99.44\% and $98.50-99.51 \%$ for mangrove (Kandelia
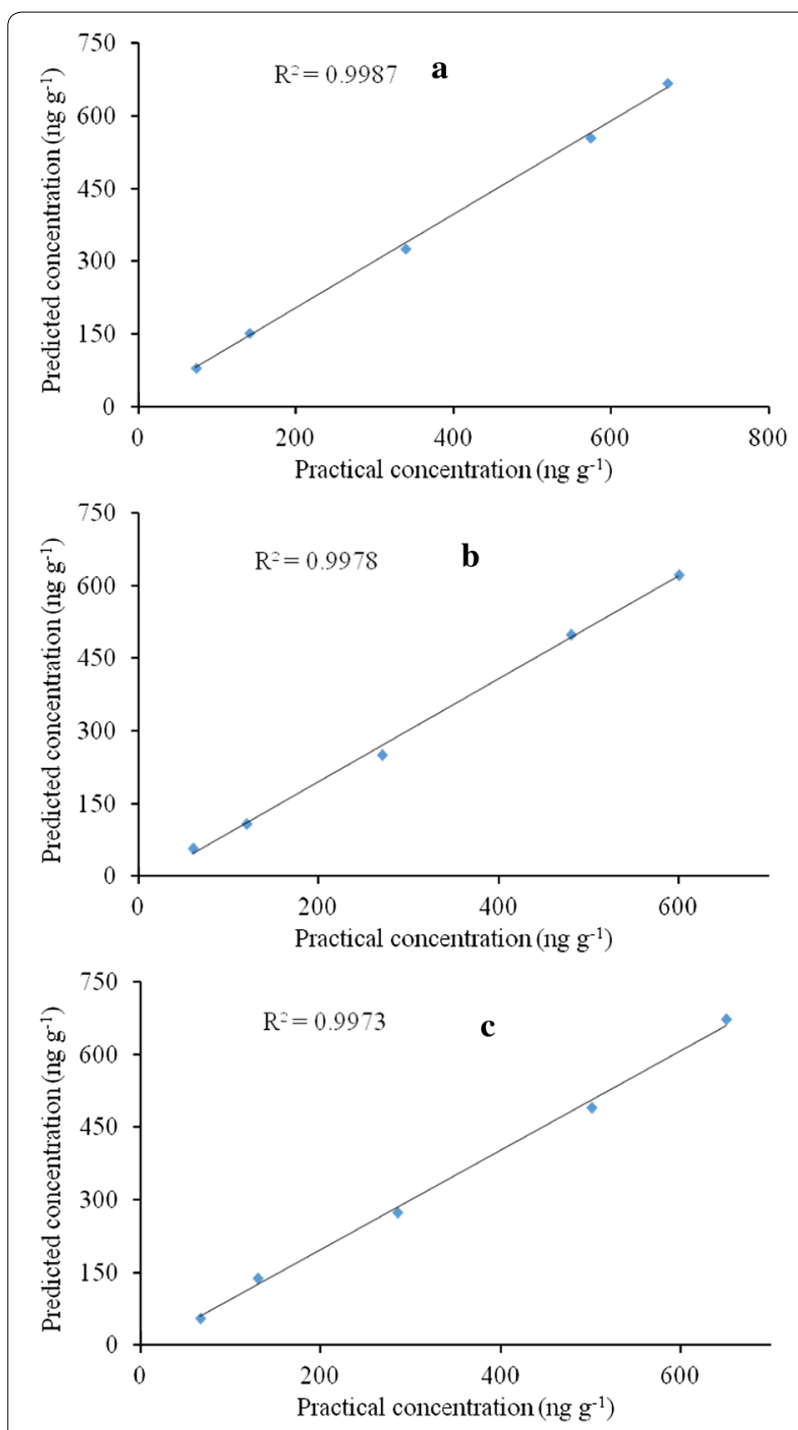

Fig. 1 The predicted concentration derived by n-PLS versus practical concentrations for a oleic acid-CdS/ZnS QDs, b PEG-COOH-CdS/ZnS QDs and c MPA-COOH-CdS/ZnS QDs located on mangrove (Kandelia obovata (S., L.) Yong) root epidermis 
obovata (S., L.) Yong) and wheat (Triticum acstivnm L.), respectively (Additional file 1: Table S2). Overall, the observations indicated that the reliability, sensitivity and selectivity meet the requirements for establishing an in situ CdS/ZnS QD determination method.

\section{In situ investigation of the depuration fate of mixtures of CdS/ZnS QDs with different surface coatings on root epidermis \\ The dominant factors that determine their depuration fate in the rapid stage}

The kinetic depuration of multicomponent $\mathrm{CdS} / \mathrm{ZnS}$ QDs located on the root epidermis of mangrove (Kandelia obovata (S., L.) Yong) and wheat (Triticum acstivnm L.) was monitored over 7 days in the presence and absence of sterilization treatment using the established method, and the experimental results are presented in Fig. 2, Table 2 (rapid stages) and Table 3 (slow stages). The depuration of $\mathrm{CdS} / \mathrm{ZnS}$ QDs clearly followed two stages: a rapid phase in the initial $8 \mathrm{~h}\left(K_{\mathrm{r}}=\left(C_{0} / C_{\mathrm{r}}\right) / \Delta t\right)$ and a slower phase $\left(K_{\mathrm{s}}=\left(C_{\mathrm{r}} / C_{\mathrm{s}}\right) / \Delta t\right.$, where $C_{0}, C_{\mathrm{r}}$ and $C_{\mathrm{s}}$ represent the remaining concentrations of $\mathrm{CdS} / \mathrm{ZnS}$ QDs on the root epidermis at $0 \mathrm{~h}, 8 \mathrm{~h}$ and 7 days, respectively, and $\Delta t$ represents the time duration of the corresponding processes) over the last $160 \mathrm{~h}$. Zhou et al. determined that the desorption of ENMs from root surfaces and tissues can be considered negligible unless applying different metal ions, surfactants, complexing agents or ultrasonic techniques due to the strong adhesion force between ENMs and roots [39]. Thus, the main contributions to the dissipation of $\mathrm{CdS} / \mathrm{ZnS}$ QDs on root epidermis are transportation and biodegradation processes.

In this study, the total $\mathrm{Cd}$ content in the root epidermis $\left(C_{\mathrm{cd}}\right)$ was considered as an indicator of the transportation rate of the CdS/ZnS QDs because biodegradation has no effect on $C_{\mathrm{cd}}$ values (Fig. 3). As Fig. 3 displays, in both the sterilizing and non-sterilizing treatment groups, the $C_{\mathrm{cd}}$ values on the mangrove (Kandelia obovata (S., L.) Yong) roots in the rapid stage slightly decreased from 393.9 to $346.7 \mathrm{ng} \mathrm{g}^{-1}, 223.6$ to $216.9 \mathrm{ng} \mathrm{g}^{-1}$ and 217.7 to $205.5 \mathrm{ng} \mathrm{g}^{-1}$ for the oleic acid-CdS/ZnS QDs, PEG$\mathrm{COOH}-\mathrm{CdS} / \mathrm{ZnS}$ QDs and MPA-COOH-CdS/ZnS QDs, respectively $(p>0.05)$. Similar results were obtained for the wheat (Triticum acstivnm L.) root. These results indirectly indicated that biodegradation rather than transportation of CdS/ZnS QDs in roots may have a dominative effect on the clearance during the rapid phase. Furthermore, no obvious differences between the $K_{\mathrm{r}}$ values of the sterilizing and nonsterilizing treatment groups contaminated with mixtures of oleic acid-CdS/ZnS QDs, PEG-COOH-CdS/ZnS QDs and MPA-COOH-CdS/ ZnS QDs were observed in the rapid depuration stage (Table 2, $p<0.05$ ), which indicated that degradation did
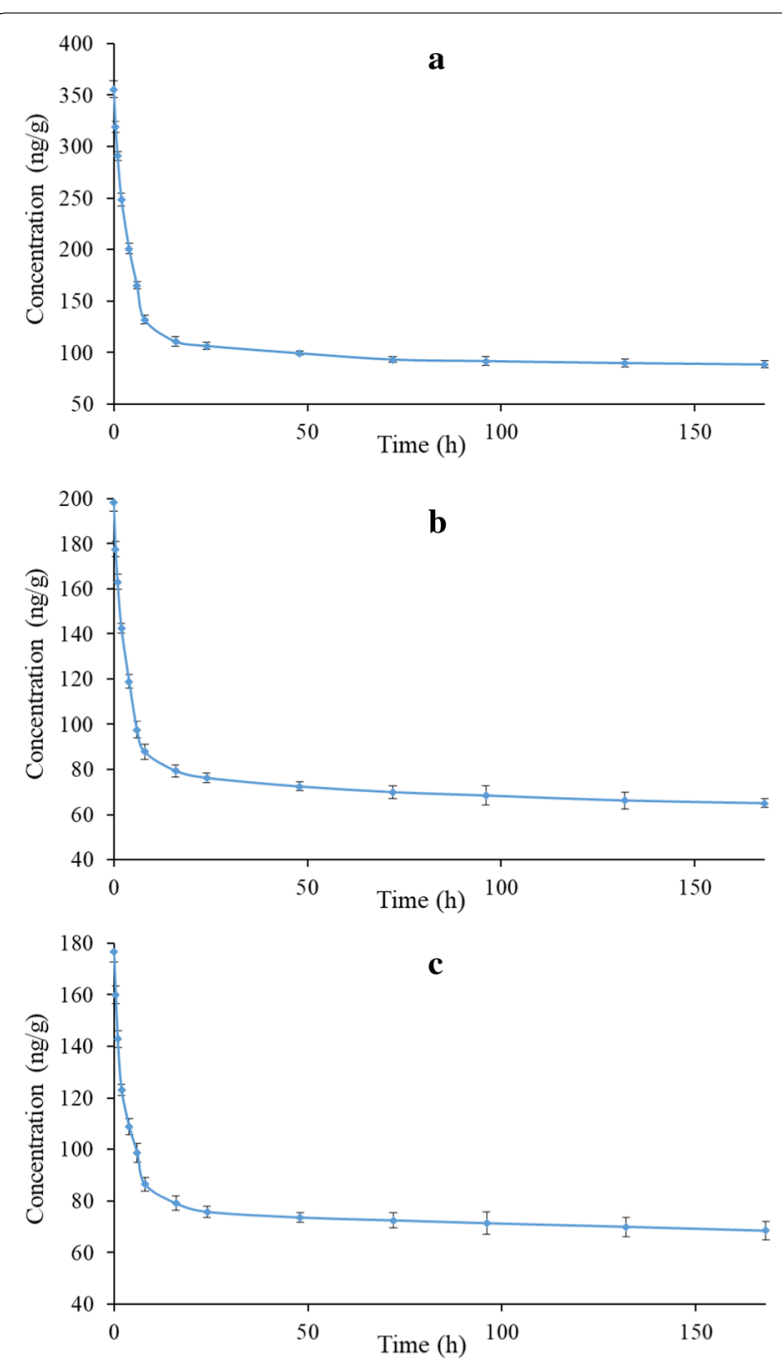

Fig. 2 The depuration rates of mixtures of CdS/ZnS QDs located on mangrove (Kandelia obovata (S., L.) Yong) root epidermis with the sterilization treatment a oleic acid-CdS/ZnS QDs, b PEG-COOH-CdS/ ZnS QDs and c MPA-COOH-CdS/ZnS QDs

not originate from plant-associated rhizophytic bacteria $[40,41]$.

Except for in vitro microbial degradation, Kwon et al. reported that metal-based QDs can be degraded in both intracellular and intercellular spaces of freshwater invertebrates (Daphnia magna) because QDs have small sizes that easily penetrate the cell membranes of protoplasts [42]. In contrast to animal cells, in general, the transportation and transformation of exotic substances (e.g., PAHs, PCBs, metal oxides nanoparticles and so on) in root cells can be ignored due to strong adsorption and absorption by cell walls [43, 44]. However, after exposure for $8 \mathrm{~h}$, the fluorescence lifetime imaging microscopy (FLIM) images displayed that the CdS/ZnS QDs formed large cluster in both the intracellular and intercellular 
Table 2 The concentrations of CdS/ZnS QDs located on root epidermis after the exposure of $8 \mathrm{~h}$ (rapid depuration stages)

\begin{tabular}{|c|c|c|c|c|c|c|}
\hline \multirow[t]{2}{*}{ Plant } & \multirow[t]{2}{*}{ QDs } & \multirow[t]{2}{*}{$C_{0}\left(\mathrm{ng} \mathrm{g}^{-1}\right)$} & \multicolumn{2}{|c|}{ Sterilization treatment } & \multicolumn{2}{|c|}{ Non-sterilization treatment } \\
\hline & & & $C_{\mathrm{r}}\left(\mathrm{ng} \mathrm{g}^{-1}\right)$ & $K_{\mathrm{r}}\left(\mathrm{h}^{-1}\right)$ & $C_{r}\left(\mathrm{ng} \mathrm{g}^{-1}\right)$ & $K_{\mathrm{r}}\left(\mathrm{h}^{-1}\right)$ \\
\hline \multirow[t]{3}{*}{ Mangrove } & Oleic acid-CdS/ZnS QDs & $355.6^{\mathrm{a}} \pm 8.2^{\mathrm{b}}$ & $131.9 \pm 4.1$ & 0.3851 & $133.8 \pm 4.9$ & 0.3796 \\
\hline & PEG-COOH-CdS/ZnS QDs & $198.4 \pm 4.0$ & $87.8 \pm 3.5$ & 0.3228 & $90.2 \pm 3.2$ & 0.3142 \\
\hline & MPA-COOH-CdS/ZnS QDs & $176.6 \pm 3.9$ & $86.5 \pm 2.6$ & 0.2917 & $84.4 \pm 1.7$ & 0.2989 \\
\hline \multirow[t]{3}{*}{ Wheat } & Oleic acid-CdS/ZnS QDs & $289.7 \pm 6.3$ & $121.5 \pm 8.1$ & 0.3406 & $111.4 \pm 5.9$ & 0.3715 \\
\hline & PEG-COOH-CdS/ZnS QDs & $155.2 \pm 5.1$ & $81.3 \pm 4.6$ & 0.2727 & $85.5 \pm 2.6$ & 0.2593 \\
\hline & MPA-COOH-CdS/ZnS QDs & $167.8 \pm 2.6$ & $84.0 \pm 1.3$ & 0.2497 & $81.7 \pm 2.5$ & 0.2934 \\
\hline
\end{tabular}

a Mean values of the concentrations of CdS/ZnS QDs located on root epidermis of six groups

b Standard deviations of the concentrations of CdS/ZnS QDs located on root epidermis of six groups

Table 3 The concentrations of CdS/ZnS QDs located on root epidermis after the exposure of 7 days (slow depuration stages)

\begin{tabular}{|c|c|c|c|c|c|c|c|}
\hline \multirow[t]{2}{*}{ Plant } & \multirow[t]{2}{*}{ QDs } & \multicolumn{3}{|c|}{ Sterilization treatment } & \multicolumn{3}{|c|}{ Non-sterilization treatment } \\
\hline & & $C_{\mathrm{r}}\left(\mathrm{ng} \mathrm{g}^{-1}\right)$ & $C_{s}\left(\mathrm{ng} \mathrm{g}^{-1}\right)$ & $K_{\mathrm{s}}\left(\mathrm{h}^{-1}\right)$ & $C_{\mathrm{r}}\left(\mathrm{ng} \mathrm{g}^{-1}\right)$ & $C_{\mathrm{s}}\left(\mathrm{ng} \mathrm{g}^{-1}\right)$ & $K_{\mathrm{s}}\left(\mathrm{h}^{-1}\right)$ \\
\hline \multirow[t]{3}{*}{ Mangrove } & Oleic acid-CdS/ZnS QDs & $131.9^{a} \pm 4.1^{b}$ & $88.5 \pm 3.5$ & $9.315 \times 10^{-3}$ & $133.8 \pm 4.9$ & $85.2 \pm 2.7$ & $9.815 \times 10^{-3}$ \\
\hline & PEG-COOH-CdS/ZnS QDs & $87.8 \pm 3.5$ & $65.1 \pm 1.9$ & $8.429 \times 10^{-3}$ & $90.2 \pm 3.2$ & $70.7 \pm 1.9$ & $7.974 \times 10^{-3}$ \\
\hline & MPA-COOH-CdS/ZnS QDs & $86.5 \pm 2.6$ & $68.5 \pm 3.7$ & $7.892 \times 10^{-3}$ & $84.4 \pm 1.7$ & $64.4 \pm 4.8$ & $8.191 \times 10^{-3}$ \\
\hline \multirow[t]{3}{*}{ Wheat } & Oleic acid-CdS/ZnS QDs & $121.5 \pm 8.1$ & $80.5 \pm 4.6$ & $9.433 \times 10^{-3}$ & $111.4 \pm 5.9$ & $75.4 \pm 4.2$ & $9.234 \times 10^{-3}$ \\
\hline & PEG-COOH-CdS/ZnS QDs & $81.3 \pm 4.6$ & $60.7 \pm 2.9$ & $8.371 \times 10^{-3}$ & $85.5 \pm 2.6$ & $61.5 \pm 3.6$ & $8.689 \times 10^{-3}$ \\
\hline & MPA-COOH-CdS/ZnS QDs & $79.0 \pm 1.3$ & $59.6 \pm 1.9$ & $8.284 \times 10^{-3}$ & $81.7 \pm 2.5$ & $63.8 \pm 5.1$ & $8.004 \times 10^{-3}$ \\
\hline
\end{tabular}

a Mean values of the concentrations of CdS/ZnS QDs located on root epidermis of six groups

b Standard deviations of the concentrations of CdS/ZnS QDs located on root epidermis of six groups

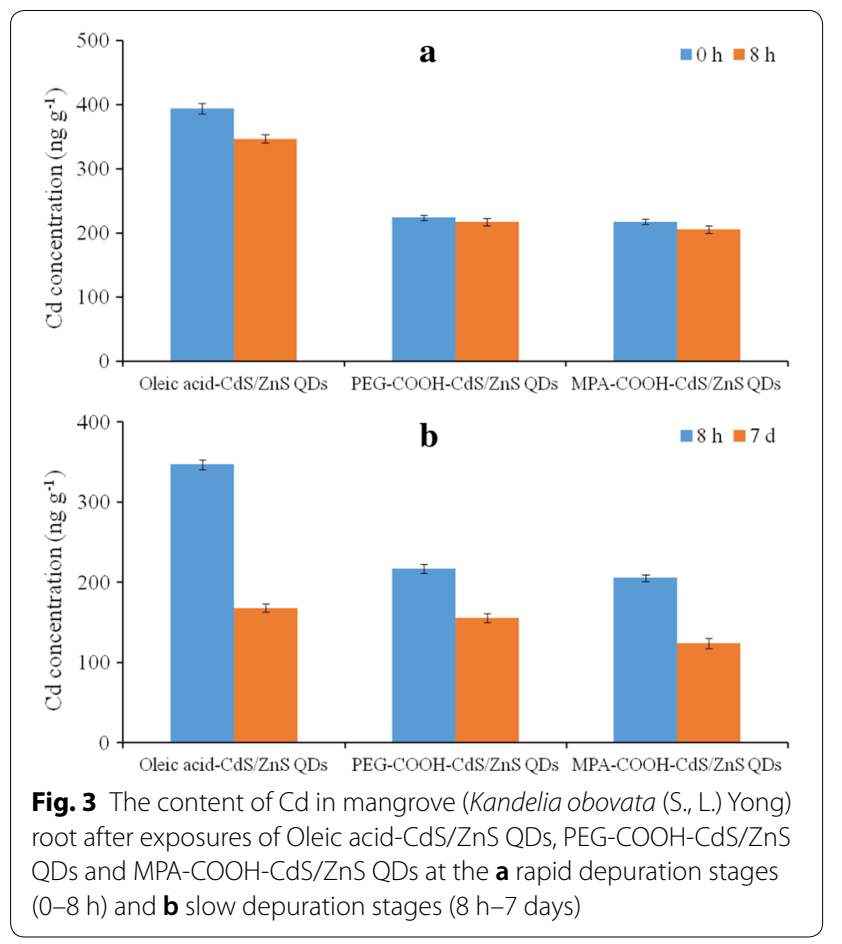

space of root epidermis cell (Additional file 1: Figure S5) [the green and yellow colour represented the fluorescence signal of CdS/ZnS QDs (>15 ns) and auto-fluorescence signal of root $(<10 \mathrm{~ns})$ separately]. This result demonstrated that the degradations of metal-based QDs may happen in the intracellular and intercellular of root epidermis cell. The surface coating of metal-based QDs prevents nanoparticle degradation and ion leakage.

To better clarify the degradation mechanisms, we compared the differences in the $K_{\mathrm{r}}$ values between the single and mixture $\mathrm{CdS} / \mathrm{ZnS}$ QDs located on the root epidermis. Interestingly, we found that obvious differences between the $K_{\mathrm{r}}$ values of these two groups were obtained for the PEG-COOH-CdS/ZnS QDs and MPA-COOH$\mathrm{CdS} / \mathrm{ZnS}$ QDs, while the oleic acid-CdS/ZnS QD exposure groups were not different $(p<0.05)$. Meanwhile, the $K_{\mathrm{r}}$ values of the oleic acid-CdS/ZnS QDs located on mangrove (Kandelia obovata (S., L.) Yong) and wheat (Triticum acstivnm L.) root epidermis samples, i.e., $0.3851 \mathrm{~h}^{-1}$ and $0.3406 \mathrm{~h}^{-1}$, respectively, were much higher than those of PEG-COOH-CdS/ZnS QDs and MPA-COOHCdS/ZnS QDs (Table 2, $p<0.05$ ). These two results 
indicate that the reactions or strong molecular interactions ( $n-\pi$, hydrogen bonds and so on) between PEG$\mathrm{COOH}-$ and MPA-COOH- may improve the stability of these two $\mathrm{CdS} / \mathrm{ZnS}$ QDs and affect the rapid degradation rate [45].

\section{The dominant factors that determine their depuration fate in the slow stage}

Two dissimilar results were found for the dissipation of the CdS/ZnS QD mixtures in the slow stage from $8 \mathrm{~h}$ to 7 days. In detail, (1) the depuration rates of the singlecomponent CdS/ZnS QDs were much higher than those of the mixture QDs on the mangrove (Kandelia obovata (S., L.) Yong) root $(p<0.05$, Additional file 1: Figure S6 and Fig. 2); (2) the $C_{\mathrm{cd}}$ contents of the oleic acid-CdS/ZnS QDs, PEG-COOH-CdS/ZnS QDs and MPA-COOH$\mathrm{CdS} / \mathrm{ZnS}$ QDs with the sterilization treatment on the mangrove (Kandelia obovata (S., L.) Yong) root significantly decreased from 346.7 to $167.7 \mathrm{ng} \mathrm{g}^{-1}, 216.9$ to $155.5 \mathrm{ng} \mathrm{g}^{-1}$ and 205.5 to $123.9 \mathrm{ng} \mathrm{g}^{-1}$, respectively (Fig. 3b). Similar results were obtained for wheat (Triticum acstivnm L.). Our data suggested that the mechanisms in the rapid dissipation stage of the CdS/ZnS QDs are not suitable for the slow stage, and thus, selective transportation processes may be involved in the depuration process.

To confirm our assumptions, after exposure for 7 days, FLIM was used to in situ track the migration of $\mathrm{CdS} / \mathrm{ZnS}$ QDs in a mangrove (Kandelia obovata (S., L.) Yong) plant Yong root (Additional file 1: Figure S7) [46]. From the figures, it can be clearly concluded that a large number of blue spot were founded in both the divisional, elongation and root hair zones, which indicated that these three kinds of $\mathrm{CdS} / \mathrm{ZnS}$ QDs transported and located on the above sections. Meanwhile, no detectable levels of CdS/ $\mathrm{ZnS}$ QDs were observed in the cortex and vascular tissues. Therefore, longitudinal rather than radial movements participate in the slow depuration stage of $\mathrm{CdS} /$ $\mathrm{ZnS}$ QDs located on root epidermis. Similar results were also obtained for the wheat (Triticum acstivnm L.) plant.

As many reports have displayed, the rates of transportation of ENMs in plants are affected by two aspects:
[47-49] First, the chemical compositions of root epidermal cell wall, which consists of cellulose, lignin, hemicellulose and so on, acts as an effective sorption phase for ENM transport through intercellular pathways (apoplastic movement), and thus, the cell wall may be the first barrier for both spatial and vertical transportation of metal-based QDs [50]. Second, symplastic or endocytosis by membrane cell protoplasts is an another important pathway for nanomaterial transportation, especially for ENMs that mainly move through intracellular pathways $[51,52]$.

Therefore, to further explore the transportation mechanisms, the distributions of carbon (C), oxygen $(\mathrm{O})$, nitrogen $(\mathrm{N})$ and sulfur $(\mathrm{S})$ on the mangrove (Kandelia obovata (S., L.) Yong) and wheat (Triticum acstivnm L.) roots were first detected using a previously reported method [33]. The calculated polarity indexes $((\mathrm{O}+\mathrm{N}) / \mathrm{C})$ of the mangrove (Kandelia obovata (S., L.) Yong) and wheat (Triticum acstivnm L.) roots epidermis samples were 0.60 and 0.65 , respectively (Table 4). Moreover, the $K_{\mathrm{s}}$ values of the oleic acid-CdS/ZnS QDs, which have relatively strong hydrophobic surface ligands, significantly and negatively correlated with the polarity index of the mangrove (Kandelia obovata (S., L.) Yong) $\left(R^{2}=0.9013, p<0.05\right)$ and wheat (Triticum acstivnm L.) roots $\left(R^{2}=0.9046, p<0.05\right)$. These findings revealed that apoplastic movement was the predominant movement form of the oleic acid-CdS/ZnS QDs, and thus, the interactions between the root epidermal cells and QDs limit the dissipation rate.

For the PEG-COOH-CdS/ZnS QDs and MPA-COOH$\mathrm{CdS} / \mathrm{ZnS}$ QDs, no correlations were detected between their $K_{\mathrm{s}}$ values and polarity index for both the mangrove (Kandelia obovata (S., L.) Yong) and wheat (Triticum acstivnm L.) roots, revealing that the slow depuration step consisted of both degradation and transportation pathways. In addition, after exposure to QDs for a few days, as $\mathrm{Li}$ et al. reported [49], plants have a negative physiological response, including enhanced root/stem length, which changes the QD depuration rate on the root epidermis. However, the contributions of these three processes to the slow depuration step of these two QDs

Table 4 The elemental composition of root epidermis and its relationships with the $K_{\mathrm{s}}$ values

\begin{tabular}{|c|c|c|c|c|c|c|c|c|c|c|c|}
\hline \multirow[t]{2}{*}{ Root } & \multirow[t]{2}{*}{$\mathrm{C}(\%)$} & \multirow[t]{2}{*}{$\mathrm{O}(\%)$} & \multirow[t]{2}{*}{$\mathrm{N}(\%)$} & \multirow[t]{2}{*}{ S (\%) } & \multirow[t]{2}{*}{$(\mathrm{O}+\mathrm{N}) / \mathrm{C}$} & \multicolumn{3}{|c|}{ Oleic acid-CdS/ZnS QDs ${ }^{\mathrm{a}}$} & \multicolumn{3}{|c|}{ PEG-COOH-/MPA-COOH-CdS/ZnS QDs } \\
\hline & & & & & & $K_{\mathrm{s}}\left(\mathrm{h}^{-1}\right)$ & $R^{2(\mathbf{b})}$ & $p^{c}$ & $K_{\mathrm{s}}\left(\mathrm{h}^{-1}\right)$ & $R^{2}$ & $p$ \\
\hline & 61.39 & 32.77 & 4.34 & 1.50 & 0.60 & $9.315 \times 10^{-3}$ & 0.9013 & 0.032 & $8.429 \times 10^{-3} / 8.371 \times 10^{-3}$ & $0.2079 / 0.4442$ & $0.831 / 0.704$ \\
\hline Wheat & 59.82 & 33.61 & 5.14 & 1.43 & 0.65 & $9.433 \times 10^{-3}$ & 0.9346 & 0.040 & $7.892 \times 10^{-3} / 8.284 \times 10^{-3}$ & $0.3318 / 0.3695$ & $0.902 / 0.721$ \\
\hline
\end{tabular}

\footnotetext{
a The relationships between the polarity index $((\mathrm{O}+\mathrm{N}) / \mathrm{C})$ of root and the $K_{\mathrm{s}}$ values

b $R^{2}$ represents the correlation coefficients

c $p$ represents the significantly level, $p<0.05$ indicates the correlation is significant
} 
located on the root epidermis remain unclear. Additional work is required to address this scientific issue.

\section{Practical application}

As Additional file 1: Table S3 summarized, several typical analytical methods (including the electron microscopy, optical microscopy, ICP-MS and so on) have been widely used to investigate the distribution and location of metal-based nanoparticles in various types of plant. Unfortunately, the disadvantages made them unable to in situ explore the transportation and transformations of mixtures of metal-based QDs in plant tissues. Our established method has effectively overcome such drawbacks and realized our goals using the excitation-emission matrix combined with multi-way parallel factor analysis (PARAFAC) and n-way partial least squares (n-PLS) approach.

\section{Future applications and developments of the newly established method}

It is important to note that the newly established method can be used in exploring various environmental behaviors of metal-based QDs in plants or their rhizosphere, not only the depuration of CdS/ZnS QDs in epidermis. For example, their highly sensitivity indicated that this method has the ability to explore the processes and mechanisms of trace content of metal-based QDs exchanged in sediment/water-root interface and air-leaf interface. Besides, due to the existences of spatial resolution capability, the transportation and transformations of metal-based QDs can also be explored in other plant tissues (xylem, phloem and so on).

More studies are needed to further improve the resolution of our established method. Specifically, the method has provided a new approach to in situ investigate the degradation, uptake and transportation of metal-based QDs in plant, especially in the horizontal direction. In other words, most of the processes that take place in the vertical direction cannot be easily explored by our established method due to the relative small $\mathrm{z}$-direction spatial resolution. Fortunately, the super resolution fluorescence microscopy, as many report displayed $[53,54]$, allows the observation of plant tissues in vertical direction and images their three-dimensional (3D) structure. After combination with such techniques, therefore, our method will have the capability to overcome the drawbacks described above.

\section{Conclusions}

In this study, the experimental results showed that a combination of excitation-emission matrix and PARAFAC/nPLS techniques provides a novel approach to accurately determine mixtures of metal-based QDs located on root epidermis. Then, the depuration of $\mathrm{CdS} / \mathrm{ZnS}$ QDs on root epidermis was investigated by the established method, and depuration proceeded via a rapid phase and a slow phase. The intracellular and intercellular reactions of the surface coating determined the depuration rate of the CdS/ZnS QDs $\left(K_{\mathrm{r}}\right)$ during the rapid phase, while the polarity index $((\mathrm{O}+\mathrm{N}) / \mathrm{C})$ of the root epidermis may play an important role in limiting the $K_{\mathrm{s}}$ value of the oleic acid-CdS/ZnS QDs.

\section{Additional file}

Additional file 1. Instruments and measuring conditions.

\section{Abbreviations \\ QDs: quantum dots; ENMs: engineered nanomaterials; TPLCSM: two-photon laser confocal scanning fluorescence microscopy; NPs: nanoparticles (NPs); PAA: polyacrylic acid; PEl: polyethylenimine; ICP-MS: inductively coupled plasma-mass spectrometry; NTFS: nanosecond time-resolved fluorescence spectroscopy; PARAFAC: parallel factor analysis; n-PLS: n-way partial least squares; PAHs: polycyclic aromatic hydrocarbons; A.R.: analytical grade reagents; EDS: energy-dispersive spectrometer; ANOVA: analysis of variance ANOVA; S/N: signal/noise; FLIM: fluorescence lifetime imaging microscopy.}

\section{Authors' contributions}

All authors contributed on specific aspects of the manuscript. All authors read and approved the final manuscript.

\section{Author details}

1 School of Marine Sciences, Guangxi University, Nanning 530004, People's Republic of China. ${ }^{2}$ Coral Reef Research Center of China, Guangxi University, Nanning 530004, People's Republic of China. ${ }^{3}$ Guangxi Laboratory on the Study of Coral Reefs in the South China Sea, Guangxi University, Nanning 530004, People's Republic of China.

\section{Acknowledgements}

Not applicable.

\section{Competing interests}

The authors declare that they have no competing interests.

Availability of data and materials

Not applicable.

Consent for publication

Not applicable.

Ethics approval and consent to participate

Not applicable.

Funding

This research was funded by the Natural Science Foundation of China (Nos. 91428203, 21806026, 41673105 and 41273139), MEL Visiting Fellowship (MELRS1744) and the BaGui Scholars Program Foundation (2014).

\section{Publisher's Note}

Springer Nature remains neutral with regard to jurisdictional claims in published maps and institutional affiliations.

Received: 27 December 2018 Accepted: 21 February 2019

Published online: 11 March 2019 


\section{References}

1. Zhou W, Coleman JJ (2016) Semiconductor quantum dots. Curr Opin Solid St M 20(6):352-360

2. Bundschuh M, Filser J, Luderwald S, McKee MS, Metreveli G, Schaumann GE, Schulz R, Wagner S (2018) Nanoparticles in the environment: where do we come from, where do we go to? Environ Sci Eur 30:6

3. Sun $H, N a n Y$, Feng $R, M a R$ (2018) Novel method for in situ investigation into graphene quantum dots effects on the adsorption of nitrated polycyclic aromatic hydrocarbons by crop leaf surfaces. Ecotoxicol Environ Saf 162:10-16

4. Kuhnel D, Marquardt C, Nau K, Krug HF, Mathes B, Steinbach C (2016) Environmental impacts of nanomaterials: providing comprehensive information on exposure, transport and ecotoxicity - the project DaNa2.0. Environ Sci Eur 26:21

5. Wang D (2016) Biological effects, translocation, and metabolism of quantum dots in the nematode Caenorhabditis elegans. Toxicol Res 5:1003-1011

6. Zhou C, Vitiello V, Pellegrini D, Wu C, Morelli E, Buttino I (2016) Toxicological effects of $\mathrm{CdSe} / \mathrm{ZnS}$ quantum dots on marine planktonic organisms. Ecotoxicol Environ Saf 123:26-31

7. Poirier I, Pallud M, Kuhn L, Hammann P, Demortière A, Jamali A, Chicher J, Caplat C, Gallon RK, Bertrand M (2018) Toxicological effects of CdSe nanocrystals on the marine diatom Phaeodacty/um tricornutum: the first mass spectrometry-based proteomic approach. Ecotoxicol Environ Saf 152:78-90

8. Pasquali F, Agrimonti C, Pagano L, Zappettini A, Villani M, Marmiroli M, White JC, Marmiroli N (2017) Nucleo-mitochondrial interaction of yeast in response to cadmium sulphide quantum dot exposure. J Hazard Mater 324:744-752

9. Modlitbova P, Porizka P, Novotny K, Drbohlavova J, Chamradova I, Farka Z, Zlamalova-Gargosova H, Romih T, Kaiser J (2018) Short-term assessment of cadmium toxicity and uptake from different types of $\mathrm{Cd}$-based quantum dots in the model plant Allium cepa L. Ecotoxicol Environ Saf 153:23-31

10. Awet TT, Kohl Y, Meier F, Straskraba S, Grun AL, Ruf T, Jost C, Drexel R, Tunc E, Emmerling C (2018) Effects of polystyrene nanoparticles on the microbiota and functional diversity of enzymes in soil. Environ Sci Eur 30:11

11. Hund-Rinke K, Schlich K, Wenzel A (2010) $\mathrm{TiO}_{2}$ nanoparticles-relationship between dispersion preparation method and ecotoxicity in the algal growth test. Umweltwiss Schadst Forsch 22(5):517-528

12. Schlich K, Klawonn T, Terytze K, Hund-Rinke K (2013) Hazard assessment of a silver nanoparticle in soil applied via sewage sludge. Environ Sci Eur 25:17

13. Al-Salim N, Barraclough E, Burgess E, Clothier B, Deurer M, Green S, Malone L, Weir G (2011) Quantum dot transport in soil, plants, and insects. Sci Total Environ 409(17):3237-3248

14. Das S, Wolfson BP, Tetard L, Tharkur J, Bazata J, Santra S (2015) Effect of $\mathrm{N}$-acetyl cysteine coated CdS: Mn/ZnS quantum dots on seed germination and seedlings growth of snow pea (Pisum sativum L.): imaging and spectroscopic studies. Environ Sci Nano 2:203-212

15. Koo Y, Wang J, Zhang Q, Zhu H, Wassim Chehab E, Colvin VL, Alvarez PJ, Braam J (2015) Fluorescence reports intact quantum dot uptake into roots and translocation to leaves of Arabidopsis thaliana and subsequent ingestion by insect herbivores. Environ Sci Technol 49(1):626-632

16. Zhang W, Ebbs SD, Musante C, White JC, Gao C, Ma X (2015) Uptake and accumulation of bulk and nanosized cerium oxide particles and ionic cerium by radish (Raphanus sativus L.). J Agric Food Chem 63(2):382-390

17. Ma Y, Zhang P, Zhang Z, He X, Zhang J, Ding Y, Zhang J, Zheng L, Guo Z, Zhang L, Chai Z, Zhao Y (2015) Where does the transformation of precipitated ceria nanoparticles in hydroponic plant take place? Environ Sci Technol 49(17):10667-10674

18. Montes A, Bisson MA, Gardella JA Jr, Aga DS (2017) Uptake and transformations of engineered nanomaterials: critical responses observed in terrestrial plants and the model plant Arabidopsis thaliana. Sci Total Environ 607-608:1497-1516

19. McKee MS, Filser J (2016) Impacts of metal-based engineered nanomaterials on soil communities. Environ Sci Nano 3:506-533

20. Kim JH, Oh Y, Yoon H, Hwang I, Chang YS (2015) Iron nanoparticleinduced activation of plasma membrane $\mathrm{H}^{+}$-ATPase promotes stomatal opening in Arabidopsis thaliana. Environ Sci Technol 49(2):1113-1119
21. Janicka M, Wdowikowska A, Klobus G (2017) In assay of plasma membrane $\mathrm{H}^{+}$-ATPase in plant tissues under abiotic stresses. In: Mock HP, Matros A, Witzel K (eds) Plant membrane proteomics. Methods in molecular biology, Vol 1696. New York, pp 205-215

22. Yu X, Chen B, He M, Wang H, Hu B (2018) Chip-based magnetic solid phase microextraction coupled with ICP-MS for the determination of Cd and Se in HepG2 cells incubated with CdSe quantum dots. Talanta 179:279-284

23. Sun H, Guo S, Nan Y, Ma H (2018) Direct determination of surfactant effects on the uptake of gaseous parent and alkylated PAHs by crop leaf surfaces. Ecotoxicol Environ 154:206-213

24. Bendicho C, Bendicho-Lavilla C, Lavilla I (2016) Nanoparticle-assisted chemical speciation of trace elements. Trend Anal Chem 77:109-121

25. Wang S, Li L, Jin S, Li W, Hang W, Yan X (2017) Rapid and quantitative measurement of single quantum dots in a sheath flow cuvette. Anal Chem 89(18):9857-9863

26. Wang J, Li N, Shao F, Han H (2015) Microwave-assisted synthesis of highquality CdTe/CdS@ZnS-SiO, near-infrared-emitting quantum dots and their applications in $\mathrm{Hg}^{2+}$ sensing and imaging. Sensor Actuators B Chem 207:74-82

27. Sousa JCL, Vivas MG, Ferrari JL, Mendonca CR, Schiavon MA (2014) Determination of particle size distribution of water soluble CdTe quantum dots by optical spectroscopy. RSC Adv 4(68):36024-36030

28. Lewinski NA, Zhu H, Jo JH, Pham D, Kamath RR, Ouyang CR, Vulpe CD, Colvin VL, Drezek RA (2010) Quantification of water solubilised CdSe/ZnS quantum dots in Daphnia magna. Environ Sci Technol 44(5):1841-1846

29. Li RL, Tan HD, Zhu YX, Zhang Y (2017) The retention and distribution of parent, alkylated, and N/O/S-containing polycyclic aromatic hydrocarbons on the epidermal tissue of mangrove seedlings. Envion Pollut 226:135-142

30. Li RL, Sun HF, Wang SP, Wang YH, Yu KF (2018) Retention of CdS/ZnS quantum dots (QDs) on the root epidermis of woody plant and its implications by benzo[a]pyrene: evidence from the in situ synchronous nanosecond time-resolved fluorescence spectra method. J Agric Food Chem 66(4):814-821

31. Carabajal MD, Arancibia JA, Escandar GM (2017) Excitation-emission fluorescence-kinetic data obtained by Fenton degradation. Determination of heavy-polycyclic aromatic hydrocarbons by four-way parallel factor analysis. Talanta 165:52-63

32. Yang R, Zhao N, Xiao X, Yu S, Liu J, Liu W (2016) Determination of polycyclic aromatic hydrocarbons by four-way parallel factor analysis in presence of humic acid. Spectrochim Acta A 152:384-390

33. Patra D, Ghaddar TH (2009) Application of synchronous fluorescence scan spectroscopy for size dependent simultaneous analysis of CdTe nanocrystals and their mixtures. Talanta 77(4):1549-1554

34. Yang R, Zhao N, Xiao X, Yin G, Yu S, Liu J, Liu W (2016) Quantifying PAHs in water by three-way fluorescence spectra and second-order calibration methods. Opt Express 24(14):A1148-A1157

35. Coombs JT, Franco CMM (2003) Isolation and identification of actinobacteria from surface-sterilized wheat roots. Appl Environ Microbiol 69(9):5603-5608

36. Tan HD, Li RL, Zhu YX, Zhang Y (2017) In situ quantitative and visual investigation of the retention of polycyclic aromatic hydrocarbons on the root surface of Kandelia obovata using a microscopic fluorescence spectral analysis method. Talanta 167:86-93

37. Peng L, He M, Chen B, Qiao Y, Hu B (2015) Metallomics study of CdSe/ZnS quantum dots in HepG2 cells. ACS Nano 9(10):10324-10334

38. Li R, Zhu Y, Zhang Y (2015) In situ investigation of the mechanisms of the transport to tissues of polycyclic aromatic hydrocarbons adsorbed onto the root surface of Kandelia obovata seedlings. Environ Pollut 201:100-106

39. Zhou D, Jin S, Li L, Wang Y, Weng N (2011) Quantifying the adsorption and uptake of CuQ nanoparticles by wheat roots based on chemical extractions. J Environ Sci 23(11):1852-1857

40. Khan S, Afzal M, lqbal S, Khan QM (2013) Plant-bacteria partnerships for the remediation of hydrocarbon contaminated soils. Chemosphere 90(4):1317-1332

41. Guo M, Gong Z, Miao R, Rookes J, Cahill D, Zhuang J (2017) Microbial mechanisms controlling the rhizosphere effect of ryegrass on degradation of polycyclic aromatic hydrocarbons in an aged-contaminated agricultural soil. Soil Biol Biochem 113:130-142 
42. Kwon D, Kim MJ, Park C, Park J, Choi K, Yoon TH (2012) In vivo biodegradation of colloidal quantum dots by a freshwater invertebrate, Daphnia magna. Aquat Toxicol 114-115:217-222

43. Jiao XC, Xu FL, Dawson R, Chen SH, Tao S (2007) Adsorption and absorption of polycyclic aromatic hydrocarbons to rice roots. Environ Pollut 148(1):230-235

44. Galeone A, Vecchio G, Malvindi MA, Brunetti V, Cingolani R, Pompa PP (2012) In vivo assessment of CdSe-ZnS quantum dots: coating dependent bioaccumulation and genotoxicity. Nanoscale 4(20):6401-6407

45. Zarco-Fernandez S, Coto-García AM, Munoz-Olivas R, Sanz-Landaluze J, Rainieri S, Camara C (2016) Bioaccumulation of ionic cadmium and cadmium selenide quantum dots in zebrafish larvae. Chemosphere 148:328-335

46. Subashchandrabose SR, Krishnan K, Gratton E, Megharaj M, Naidu R (2014) Potential of fluorescence imaging techniques to monitor mutagenic PAH uptake by microalga. Environ Sci Technol 48(16):9152-9160

47. Jaiganesh T, Rani JDV, Girigoswami A (2012) Spectroscopically characterized cadmium sulfide quantum dots lengthening the lag phase of Escherichia coli growth. Spectrochim Acta A 92:29-32

48. Lin D, Tian X, Wu F, Xing B (2010) Fate and transport of engineered nanomaterials in the environment. J Environ Qual 39(6):1896-1908
49. Li W, Zhang Y, Zhang H, Liu Z, Su W, Chen S, Liu Y, Zhuang J, Lei B (2016) Phytotoxicity, uptake, and translocation of fluorescent carbon dots in mung bean plants. ACS Appl Mater Interfaces 8(31):19939-19945

50. Wang J, Yang Y, Zhu H, Braam J, Schnoor JL, Alvarez PJJ (2014) Uptake, translocation, and transformation of quantum dots with cationic versus anionic coatings by Populus deltoides $\times$ nigra Cuttings. Environ Sci Technol 48(12):6754-6762

51. Schwab F, Zhai G, Kern M, Turner A, Schnoor JL, Wiesner MR (2016) Barriers, pathways and processes for uptake, translocation and accumulation of nanomaterials in plants - critical review. Nanotoxicology 10(3):257-278

52. Zhang D, Hua T, Xiao F, Chen C, Gersberg RM, Liu Y, Ng WJ, Tan SK (2014) Uptake and accumulation of CuO nanoparticles and CdS/ZnS quantum dot nanoparticles by Schoenoplectus tabernaemontani in hydroponic mesocosms. Ecol Eng 70:114-123

53. Huang B, Bates M, Zhuang X (2011) Super-resolution fluorescence microscopy. Annu Rev Biochem 78:993-1016

54. Pujals S, Feiner-Gracia N, Delcanale P, Voets I, Albertazzi L (2019) Superresolution microscopy as a powerful tool to study complex synthetic materials. Nat Rev Chem 3:68-84

\section{Submit your manuscript to a SpringerOpen ${ }^{\odot}$ journal and benefit from:}

- Convenient online submission

- Rigorous peer review

- Open access: articles freely available online

- High visibility within the field

- Retaining the copyright to your article

Submit your next manuscript at $\boldsymbol{\nabla}$ springeropen.com 